ISSN 0103-5150

Fisioter. Mov., Curitiba, v. 30, n. 2, p. 277-285, Apr./June 2017

Licenciado sob uma Licença Creative Commons

DOI: http://dx.doi.org/10.1590/1980-5918.030.002.A008

\title{
Evaluation of frequency of positive exercise-induced bronchospasm between swimmers and sedentary individuals
}

\author{
Avaliação da frequência do broncoespasmo induzido por \\ exercício (BIE) positiva entre nadadores e sedentários
}

\author{
Laricy Martins da Mata ${ }^{[a]}$, Regiane Coissi Sanches ${ }^{[a]}$, Marceli Rocha Leite ${ }^{[b]}$, \\ Francis Lopes Pacagnelli ${ }^{[a]}$, Luiz Carlos Marques Vanderlei ${ }^{[c]}$, Flávio Danilo Mungo Pissulin ${ }^{[a]}$
}

[a] Universidade do Oeste Paulista (Unoeste), Presidente Prudente, SP, Brazil

[b] Universidade de São Paulo (USP), São Paulo, SP, Brazil

[c] Universidade Estadual Paulista Júlio de Mesquita Filho (UNESP), Presidente Prudente, SP, Brazil

\begin{abstract}
Introduction: Despite the prevalence of prescribed asthma, there is uncertainty about the incidence of exercise-induced bronchospasm (EIB). Objective: Compare the frequency of EIB between swimmers and sedentary individuals, and observe heart rate variability during bronchial activity. Methods: In total, 18 swimmers (group 1) and 18 sedentary individuals (group 2) were included. The participants rested for 30 minutes for evaluation of HRV. Blood pressure (PA), respiratory rate (RR), and pulse oxygen saturation (SpO2) were measured. The volunteers remained seated for the spirometry test (maneuver of forced vital capacity - FVC). This was repeated 5, 10, 15, 20, and 30 minutes after the exercise test. The statistical analysis used the Student $t$, Mann Whitney, and Shapiro-Wilks tests. The significance level was $\mathrm{p}<0.05$. Results: The spirometry findings showed 3 sedentary individuals and 10 swimmers with obstructive ventilatory disorder (OVD). Only 2 of the sedentary and none of the swimmer group demonstrated positive bronchial provocation. A key criterion for diagnosing OVD, the relationship between forced expiratory volume in one second and FVC (FEV1/FVC), was
\end{abstract}

\footnotetext{
LMM: BS, e-mail: laricym.m@hotmail.com

RCS: undergrad, e-mail: regianec.sanches@hotmail.com

MRL: Doctoral Student, e-mail: marcelirocha@hotmail.com

FLP: PhD, e-mail: francispacagnelli@unoeste.br

LCMV: PhD, e-mail: lcmvanderlei@fct.unesp.br

FDMP: MS, e-mail: pissulin@gmail.com
} 
statistically lower in the swimmer group. The measures of the root mean square of the successive differences between adjacent normal RR intervals, in a time interval (RMSSD), and the standard deviation of all normal RR intervals recorded in a time interval (SDNN) were significantly higher among the athletes. Conclusion: The bronchial provocation test identified a higher prevalence of bronchospasm among sedentary individuals. However, there was a reduction in the $\mathrm{FEV}_{1} / \mathrm{FVC}$ ratio and higher HRV in the group of swimmers.

Keywords: Athletes. Asthma. Exercise-Induced Bronchospasm.

\section{Resumo}

Introdução: Apesar da prevalência da asma definida, há imprecisão sobre incidência de broncoespasmo induzido por exercício (BIE). Objetivo: Comparar a freqüência de BIE entre nadadores e sedentários, e observar a variabilidade da freqüência cardíaca durante a atividade de broncoprovocação. Métodos: Incluídos 18 nadadores (grupo 1) e 18 sedentários (grupo 2). Permaneceram por 30 minutos de repouso para a avaliação da VFC. Foi aferida a pressão arterial (PA), frequência respiratória (f) e a saturação de pulso de oxigênio (SpO2). Permaneceram sentados, para o teste de espirometria (manobra da capacidade vital forçada - CVF). Essa foi repetida em 5, 10, 15, 20 e 30 minutos após o teste de esforço. A análise estatística usou os testes $t$ de Student, Mann Whitney de Shapiro-Wilk, com nível de significância p<0,05. Resultados: A espirometria evidenciou 3 sedentários e 10 nadadores com distúrbio ventilatório obstrutivo (DVO). Apenas 2 do grupo sedentário apresentaram broncoprovocação positiva e nenhum do grupo de nadadores. Um critério fundamental para diagnosticar DVO, a relação entre o volume expiratório no primeiro segundo e a CVF (VEF1/CVF) foi estatisticamente menor no grupo de nadadores. As médias da raiz quadrada da média do quadrado das diferenças entre intervalos RR normais adjacentes, em um intervalo de tempo (RMSSD) e no desvio padrão de todos os intervalos RR normais gravados em um intervalo de tempo (SDNN), foram estatisticamente maiores entre os atletas. Conclusão: $O$ teste de broncoprovocação identificou maior prevalência de broncoespasmo entre os sedentários. Entretanto, houve redução na relação $V E F_{1} / C V F$ e maior VFC no grupo de nadadores.

Palavras-chave: Atletas. Asma. Broncoespasmo Induzido Por Exercício.

\section{Introduction}

Asthma is characterized by chronic inflammation in the airways, and severe and acute reduction in bronchial lumen, with a consequent reduction in airflow in response to bronchoconstrictor stimuli $(1,2,3)$. The average global prevalence varies between $1 \%$ and $18 \%$, depending on the country. It averages $11.6 \%$ among school children (six and seven years) and $9.5 \%$ from 0 to 17 years $(4,5)$.

Exercise-induced bronchospasm (EIB) is generated by the practice of vigorous physical activity that induces bronchospasm. It begins with five to ten minutes of physical activity, and normalization of bronchial tone after 30 to 60 minutes of rest. There is a higher prevalence of EIB in athletes who perform activities in cold climates $(6,7)$, and higher intensity activities (8), such as swimmers, cyclists and distance runners.
The perception of symptoms of EIB is low in these competitors, which inhibits diagnosis and treatment $(8,9)$. Among high-level swimmers reports of asthma and/or drug use reached $29.6 \%$ in one study (8).

Swimming has always been seen as a good treatment for asthma and bronchitis; however some individuals may develop asthma attacks during and after swimming, or worsening symptoms, either due to the exercise, chlorine inhalation, or the high frequency of rhinitis and sinusitis. Swimming aims to reeducate respiratory function, especially diaphragmatic, improving regional ventilation, in areas, which improves the ventilatory pattern. In addition, there is improved aerobic fitness, which prepares these individuals to withstand asthma attacks; many Olympic champions started this sport in order to reduce asthma attacks (9). 
EIB can be characterized as a drop in forced expiratory volume in one second $\left(\mathrm{FEV}_{1}\right)$ greater than or equal to $10 \%$. Decreases of more than $15 \%$ are mild, $20 \%$ to $30 \%$ moderate, over $30 \%$ severe (10). High performance athletes should perform spirometry and bronchial provocation tests even when they do not present a previous history of the disease.

It is not possible to affirm that physical conditioning of swimmers is a trigger of bronchoconstriction, due to the presence of greater parasympathetic tone. However, it is well established that cholinergic stimulation induces bronchoconstriction. Greater parasympathetic tone could be an adjuvant to bronchospasm when associated with the presence of a trigger (10). The high prevalence of asthma among adolescents together with the frequent complaints of dyspnea and "wheezing" in swimming athletes stimulated the proposal for the current scientific study. In this context we intend to encourage early diagnosis, so that these athletes seek preventive treatment and avoid episodes of exacerbation characterized by EIB.

Considering the above, it is possible that there would be a higher prevalence of EIB among swimmers, associated with increased parasympathetic tone, when compared to sedentary individuals.

This study aimed to compare the frequency of exercise-induced bronchoconstriction (EIB) between swimmers and sedentary individuals, and observe heart rate variability during the course of bronchial provocation activity.

\section{Methods}

The present study is transversal. In total 40 individuals of both genders were included, aged 13 to 25 years. The participants presented no past history of bronchial asthma and did not use bronchodilator medication. Group 1 was composed of 20 swimmers in a training regimen, often six days a week with a minimum of 3 hours. Group 2 included the same sample size, but was formed by sedentary individuals.

The present study was approved by the Research Ethics Committee (CEP) and Institutional Research Advisory Committee (CAPI), of the University of West Paulista (Unoeste) under CAAE protocol number 25858813.0.0000.5515. All participants signed a free and informed consent (FIC) and when necessary, the agreement term. The procedures were performed at the Clinical School of Physiotherapy, Unoeste (respiratory therapy sector).

After verification of height and weight (Filizola ${ }^{\circledR}$ scale), and calculation of the body mass index (BMI), subjects were instructed to remain for 10 minutes sitting at rest. Blood pressure was measured using a non-invasive method with a sphigometer, BD brand, pulse oxygen saturation $\left(\mathrm{SpO}_{2}\right)$, with an oximeter, NONIN brand, and respiratory rate (r), by observing the oscillations of the rib cage $(11,12)$.

\section{Autonomic Evaluation}

The Heart Rate Variability (HRV) was also determined. For this, the volunteers were instructed not to consume alcoholic beverages or autonomic nervous system stimulants, such as coffee, tea, and chocolate drinks, for at least 24 hours prior to the evaluation.

The collection was initiated after the individual had remained seated for 10 minutes in a quiet place. The measurement was performed for 30 minutes and interrupted to perform the spirometry. When the patient began the test on the treadmill, the measurement of HRV started once again until the end of the exercise test, to verify the maximum heart rate achieved.

The capture belt was positioned at the distal third of the sternum, and the HR Polar RS800 CX RUN receiver on the wrist. This equipment has been previously validated to capture HR beat to beat as well as the use of the data for analysis of HRV indices (13).

The data analysis used 1000 consecutive RR intervals. Digital complemented by manual filtering was carried out to eliminate premature ectopic beats and artifacts, and only series with more than $95 \%$ of sinus beats were included in the study (13).

For HRV analysis: nonlinear methods [DFA - Total DFA, alpha 1, alpha 2 and alpha 1/alpha 2 ratio, Recurrence plot - from which was extracted the recurrence rate (REC), determinism (DET) and approximate entropy (ApEn) - and the Poincaré plot, also being evaluated linear methods analyzed in the time (SDNN and RMSSD) and frequency domains (LF $\mathrm{HF}$ and LF/HF) and geometric methods (triangular index and TINN). The RMSSD is the root mean square of the successive differences between adjacent normal RR intervals in a time interval, expressed in ms, SDNN is the standard deviation of all normal RR intervals recorded in an interval of time expressed in $\mathrm{ms}$, HF (High Frequency) and LF (Low Frequency), SD1 is the 
standard deviation of the instantaneous variability beat to beat, SD2 is the standard deviation in the longterm of continuous RR intervals and the TINN index is the triangular interpolation of the intervals (14).

Kubios HRV analysis software version 2.0 was used to calculate these indices (15).

\section{Spirometry}

Thirty minutes after the HRV collection the spirometric test was performed. The curve of the forced vital capacity was recorded (FVC) using a spirometer, Micro Medical MK8. The subjects performed the test in a sitting position and, after inserting the nozzle, performed a maximal inspiration followed by a maximal expiration. Spirometry was performed prior to the maximal exercise test and 5, 10, 15, 20, and 30 minutes after the stress test on the treadmill. All spirometry procedures were in accordance with the guidelines for pulmonary function tests, which included temperature and humidity control maintained between 23 and 25 degrees Celsius $(3,11,12)$. The objective was to avoid large differences between the temperature of the spirometer and the body.

\section{Test to trigger exercise-induced bronchoconstriction (EIB)}

For the realization of the EIB, a treadmill, brand IMBRAMED, was used. It was programmed with a fixed inclination of $10 \%$ and speed controlled to reach a heart rate between $75 \%$ and $85 \%$ of maximal HR in the first 2 minutes. HR remained in the range between $85 \%$ and $95 \%$ of the maximum value expected until the end of test, which lasted 8 minutes.

For EIB, the test was considered positive when there was a reduction greater than $10 \%$ in forced expiratory volume in one second $\left(\mathrm{FEV}_{1}\right)$, or a decrease of $25 \%$ in forced expiratory flow between $25 \%$ and $75 \%$ of expiration $\left(\mathrm{FEF}_{25 \%-75 \%}\right)$, to compare the value of the spirometric parameter before exercise with any of the measurements taken after the stress test $(10,12)$.

\section{Statistical methods}

Data normality was tested using the ShapiroWilk test. To compare the variables with normal distribution between the groups, the Student's t test for unpaired data was applied, while for non-normal distribution, the Mann Whitney test was used. The value of significance considered was $p<0.05$.

\section{Results}

The present study evaluated 40 individuals. Of this total, 18 were sedentary ( 5 males and 13 females) and 18 were athletes, including 12 males and $6 \mathrm{fe}$ males. Two volunteers from each group refused to perform the proposed tests.

Table 1 presents the anthropometric characteristics of both groups. Significant differences were observed in height and weight between athletes and sedentary individuals $(\mathrm{p}<0.05)$. The spirometry findings also showed 3 sedentary individuals with obstructive ventilatory disorder (OVD) and 10 athletes with the same result, verified pre physical activity (Table 1), by the reduction in the $\mathrm{FEV}_{1} / \mathrm{FVC}$ ratio (Table 3 ). This table presents the values in means and therefore the reduction in the $\mathrm{FEV}_{1} / \mathrm{FVC}$ ratio is not evident.

The application of the EIB test demonstrated that 2 sedentary individuals presented a decrease greater than $25 \%$ in the FEF $25-75 \%$, as well as a reduction greater than $10 \%$ in the $\mathrm{FEV}_{1}$, comparing the values measured pre exercise and 5 minutes after the test (Figure 1). No reduction in these parameters was observed among athletes, positive bronchoprovocation did not occur in the test.

Table 2 shows the mean values of the spirometric parameters $\mathrm{FEV}_{1}$ and $\mathrm{FEF}_{25-75 \%}$, of sedentary individuals and athletes before executing the EIB test (pre) and $5,10,15,20$, and 30 minutes after testing. It can be seen that the mean $\mathrm{FEV}_{1}$, at all times, was higher $(\mathrm{p}<0.05)$ in the athletes. The FEF $25-75 \%$ behavior was similar in both groups.

The $\mathrm{FEV}_{1} / \mathrm{FVC}$ ratio was statistically lower in the group of athletes, at all measurement times, $\mathrm{p}<0.05$ (Table 3). Regarding the comparison between the times of the pre maximal stress test and 5, 10, 15, 20, and 30 minutes post-test, statistical difference was only observed in the $\mathrm{FEF}_{25-75 \%}$ at 5 and 15 minutes in the athletes, with an increase in the time of 15 minutes ( $<<0.05)$.

Table 4 presents the mean and standard deviation values of heart rate variability (HRV). The RMSSD which verifies parasympathetic tone and SDNN which verifies sympathetic tone were statistically higher in the athletes $(\mathrm{p}<0.05)$. 
Table 1 - Baseline anthropometric data, lung function data, and obstructive ventilatory disorder pre spirometric and maximum stress tests in athletes and sedentary individuals

\begin{tabular}{lccc}
\hline Parameters & Athlete & Sedentary & P value \\
\hline Age (years) & $16.28 \pm 2.67$ & $17.83 \pm 3.45^{\#}$ & 0.08 \\
Height $(\mathbf{c m})$ & $173.8 \pm 7.64$ & $162 \pm 7.19^{*}$ & $<0.0001$ \\
Weight (Kg) & $66.92 \pm 11.36$ & $56.72 \pm 11.41^{*}$ & 0.0111 \\
BMI $\left(\mathbf{K g} / \mathbf{m}^{2}\right)$ & $22.05 \pm 2.47$ & $21.52 \pm 4.26^{\#}$ & 0.3588 \\
OVD & 10 & 3 & 0.14 \\
\hline
\end{tabular}

Note: * significant difference between athlete and sedentary groups (Student's t-test for unpaired samples, $p<0.05)$. \# Significant difference between athlete and sedentary groups (Mann-Whitney t test, $\mathrm{p}<0.05$ ), BMI (body mass index), OVD (obstructive ventilatory disorder), cm

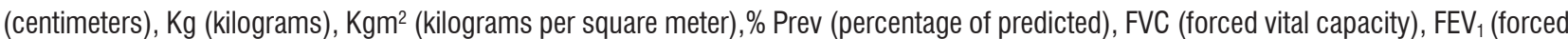
expiratory volume in one second), $\mathrm{FEV}_{1} / \mathrm{FVC}$ ratio (ratio of forced expiratory volume in one second and forced vital capacity ) and $\mathrm{FEF} 25-75 \%$ (Forced expiratory flow).

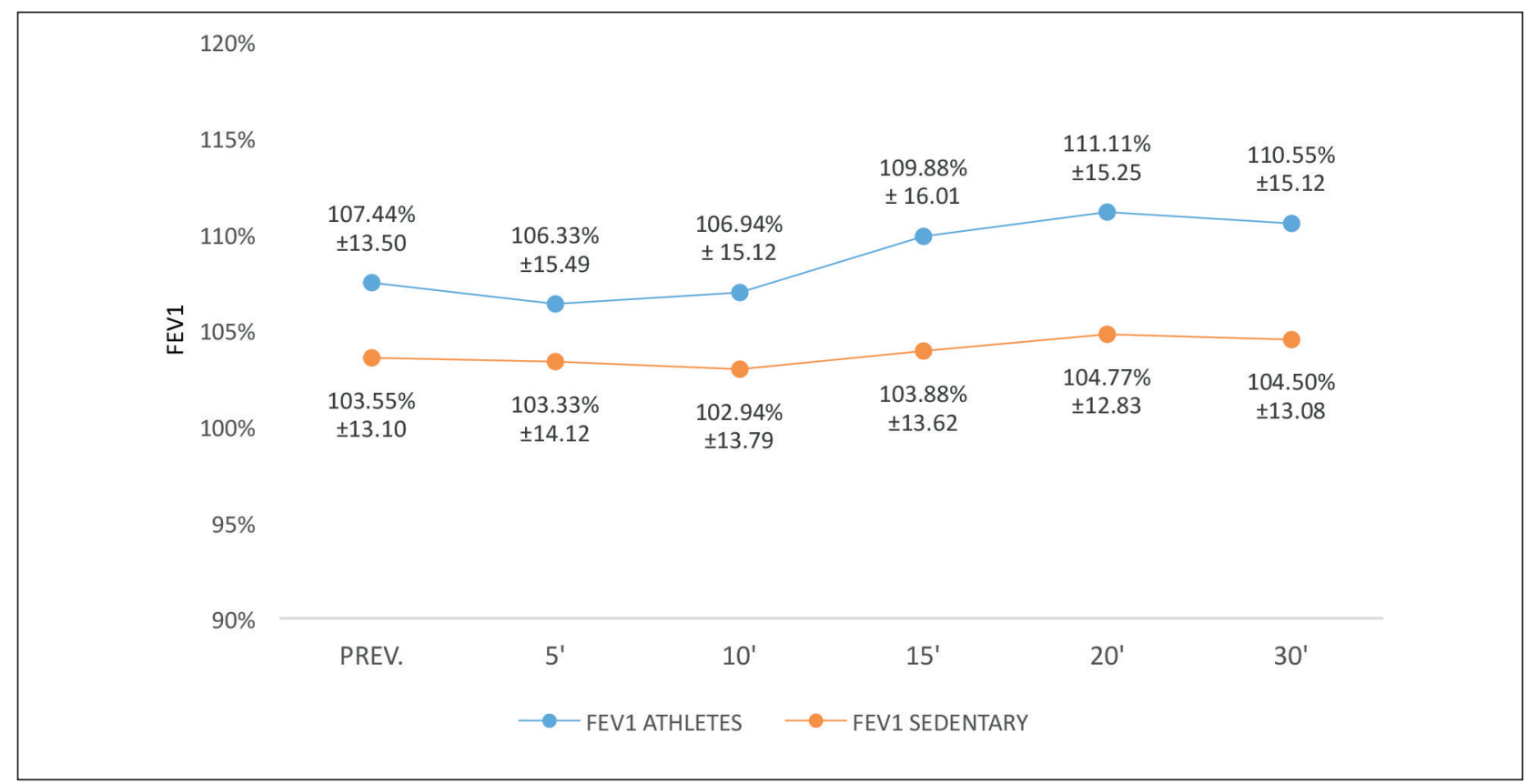

Figure 1 - Values of decrease in FEVI in sedentary individuals and athletes pre test and 5, 10, 15, 20, and 30 minutes post EIB Note: $\mathrm{FEV}_{1}$ (forced expiratory volume in one second), PREV (predicted value), 5 '(5 minutes), 10' ('10 mins), 15' (15 minutes), 20 ' (20 minutes) and 30' (30 minutes).

Table 2 - Comparison of the athletes and sedentary individuals, in the spirometric parameters FEV1, FEF 25-75, pre execution of the EIB test and 5, 10, 15, 20, and 30 minutes after the maximum stress test on the treadmill

\begin{tabular}{|c|c|c|c|c|c|c|}
\hline Times & $\mathrm{FEV}_{1} \mathrm{~A}$ & $\mathrm{FEV}_{1} \mathrm{~S}$ & $P$ value & FEF25-75\% A & FEF25-75\% S & $P$ value \\
\hline Pre & $4.03 \pm 0.74$ & $3.26 \pm 0.61^{\#}$ & 0.0015 & $3.96 \pm 0.83$ & $4.14 \pm 0.95^{\#}$ & 0.64 \\
\hline 5 minutes & $3.96 \pm 0.72$ & $3.26 \pm 0.63^{\#}$ & 0.0012 & $3.80 \pm 0.93$ & $4.04 \pm 1.02^{\#}$ & 0.43 \\
\hline 10 minutes & $4.10 \pm 0.74$ & $3.28 \pm 0.61^{\#}$ & 0.0004 & $4.06 \pm 0.95$ & $4.08 \pm 1.05^{\#}$ & 0.86 \\
\hline 15 minutes & $4.14 \pm 0.74$ & $3.28 \pm 0.63^{\#}$ & 0.0004 & $4.15 \pm 0.93$ & $4.12 \pm 1.02^{\#}$ & 0.92 \\
\hline 20 minutes & $4.15 \pm 0.72$ & $3.26 \pm 0.65^{\#}$ & 0.0003 & $4.12 \pm 0.83$ & $4.20 \pm 1.05^{\#}$ & 0.96 \\
\hline 30 minutes & $4.07 \pm 0.73$ & $3.27 \pm 0.64^{\#}$ & 0.0003 & $3.97 \pm 0.80$ & $4.13 \pm 1.02^{\#}$ & 0.91 \\
\hline
\end{tabular}

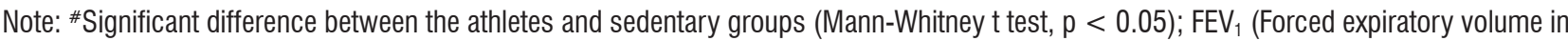
one second), FEF 25-75\% (Forced expiratory flow) 
Mata LM, Sanches RC, Leite MR, Pacagnelli FL, Vanderlei LCM, Pissulin FDM.

Table 3 - Comparison of the athlete and sedentary groups for $\mathrm{FEV}_{1} / \mathrm{FVC}(\%)$, pre execution of the EIB test and 5, 10, 15, 20 , and 30 minutes after the maximum stress test on the treadmill

\begin{tabular}{lccc}
\hline Times & FEV $_{1} /$ FVC athlete & FEV $_{1} /$ FVC sedentary & P value \\
\hline Pre & $85 \pm 6.3$ & $91 \pm 3.6^{*}$ & 0.0003 \\
$\mathbf{5}$ minutes & $83 \pm 7.5$ & $92 \pm 4^{*}$ & 0.0002 \\
$\mathbf{1 0}$ minutes & $83 \pm 6.8$ & $92 \pm 4.9^{*}$ & 0.0002 \\
$\mathbf{1 5}$ minutes & $84 \pm 6.9$ & $92 \pm 5.2^{*}$ & 0.0008 \\
$\mathbf{2 0}$ minutes & $84 \pm 7.2$ & $93 \pm 4.7^{*}$ & 0.0001 \\
$\mathbf{3 0}$ minutes & $83 \pm 6.6$ & $92 \pm 4.2^{*}$ & 0.0001 \\
\hline
\end{tabular}

Note: * Significant difference between the athlete and sedentary groups (Student's t-test for unpaired samples, $p<0.05$ ). FEV $/$ FVC (ratio of forced expiratory volume in one second and forced vital capacity).

Table 4 - Mean and standard deviation of heart rate variability between the groups of athletes and sedentary individuals evaluated before the spirometric intervention and thirty minute stress test

\begin{tabular}{lccc}
\hline & Athlete & Sedentary & P value \\
\hline RMSSD & $41.05 \pm 13.55$ & $30.59 \pm 12.14^{\#}$ & 0.0275 \\
SDNN & $65.62 \pm 17.55$ & $51.58 \pm 15.07^{\#}$ & 0.0192 \\
DFA TOT & $2.135 \pm 0.1488$ & $3.006 \pm 3.408^{*}$ & 0.3006 \\
DFA ALPHA 1 & $1.209 \pm 0.1657$ & $2.118 \pm 3.420^{\#}$ & 0.1683 \\
DFA ALPHA 2 & $0.9159 \pm 0.1164$ & $0.8883 \pm 0.1277^{*}$ & 0.5149 \\
REC & $0.311 \pm 0.0381$ & $0.3417 \pm 0.0647^{*}$ & 0.1012 \\
DET & $0.9831 \pm 0.0069$ & $0.9855 \pm 0.0087^{\#}$ & 0.1432 \\
APEN & $1.378 \pm 0.1093$ & $1.309 \pm 0.1478^{*}$ & 0.1315 \\
LF (ms) & $1496 \pm 1090$ & $941.7 \pm 562.6^{\#}$ & 0.0582 \\
LF (un) & $69.13 \pm 12.19$ & $71.41 \pm 10.92^{\#}$ & 0.7305 \\
HF (ms) & $827.5 \pm 969.2$ & $435.2 \pm 401.3^{\#}$ & 0.0629 \\
HF (un) & $30.82 \pm 12.15$ & $28.59 \pm 10.92^{\#}$ & 0.7305 \\
LF-HF & $2.674 \pm 1.308$ & $3.211 \pm 2.255^{\#}$ & 0.7305 \\
TINN & $287.1 \pm 65.03$ & $252.6 \pm 81.63^{*}$ & 0.1835 \\
SD1 & $29.06 \pm 8.589$ & $21.65 \pm 21.65^{\#}$ & $0.0287^{*}$ \\
SD2 & $88.02 \pm 23.85$ & $69.48 \pm 69.48^{\#}$ & $0.0192^{*}$ \\
\hline
\end{tabular}

Note: * Significant difference between the athlete and sedentary groups (Student's t-test for unpaired samples, $p<0.05$ ). " Significant difference between the athlete and sedentary groups (Mann-Whitney $t$ test, $p<0.05$ ), RMSSD (root mean square of the successive differences between adjacent normal RR intervals in a time interval, expressed in ms); SDNN (standard deviation of all normal RR intervals recorded in an interval of time, expressed in ms); HF ( High Frequency); HL ( Low Frequency); SD1 (standard deviation of the instantaneous variability beat to beat), SD2 (standard deviation of the long-term R-R continuous intervals); TINN: (triangular interpolation of intervals); DET (determinism); ApEn (approximate entropy); REC (recurrence rate).

\section{Discussion}

The present study verified the variation in spirometric parameters before and after the completion of an EIB protocol, comparing athletes and sedentary individuals. Of the 40 individuals assessed, 2 in the sedentary group $(11.11 \%)$ presented a positive EIB test. Among the athletes there was no positive bronchial provocation for the same test, verified through spirometric parameters.
The study by Teixeira et al. found a higher prevalence of EIB in athletes in cold climates, which may be related to air inspiration in these conditions (9). Similar behavior was found when evaluating long distance running athletes, in the same study. However, among the athletes in the present study, EIB was not observed. Perhaps the spirometric characteristic pre exercise that determined a higher prevalence of OVD (probable > FVC in some) in the population of athletes (10 individuals), influenced the response in the EIB test. 
The higher prevalence of bronchial asthma found in swimmers (8), which can be seen by the reduction in the $\mathrm{FEV}_{1} / \mathrm{FVC}$ ratio in those selected in this population, did not influence the incidence of positive bronchoprovocation through exercise. Thus, it is concluded that the trigger mechanism for the OVD found is not exercise.

The opposite can be stated for the sedentary population. This population has a lower prevalence of asthma; however the current study found positive EIB in the sedentary group. In these cases the triggering mechanism of bronchospasm was exercise, which differs from the swimmers included.

Despite the absence of positive EIB among the athletes, a reduction in $\mathrm{FEV}_{1} / \mathrm{FVC}$ was identified in 5 subjects. It is not possible to state that this finding is sensitive enough to characterize positive EIB, as well as the criteria already established by the $\mathrm{FEV}_{1}$ and $\mathrm{FEF}_{25-75 \%}$. It is possible that the reduction in the $\mathrm{FEV}_{1} / \mathrm{FVC}$ ratio, after the EIB test, efficiently characterized the presence of bronchospasm after exercise, through this parameter in isolation, diagnosing OVD.

The reduction in $\mathrm{FEV}_{1} / \mathrm{FVC}$ in individuals presenting FVC $>120 \%$ of predicted, may be a physiological variant, in the absence of symptoms and a negative post-bronchodilator spirometry test $(16,17,18,19$, $20)$. Therefore, despite 10 individuals (55.5\%) among the athletes having been diagnosed with OVD, 8 of these (44.4\%) presented FVC $>120 \%$ and of these, 5 presented a reduced $\mathrm{FEV}_{1} / \mathrm{FVC}$ ratio $(62.5 \%)$. If athletes who presented OVD and FVC $>120 \%$ are excluded, 3 athletes $(16.6 \%)$ with OVD remain, without FVC $>120 \%$, similar to the incidence of OVD found in the sedentary population.

Higher values of $\mathrm{FEV}_{1}$, found in the athletes were proportional to the greater height also observed in this population, when compared with the group of sedentary individuals. Based on the age of the individuals evaluated in this study, they were in a development phase. Through physiology constant changes in relation to growth and development take place, depending on genetic factors and extrinsic factors such as physical activity $(21,22,23,24,25,26)$.

$\mathrm{FEV}_{1}$ has increased sensitivity to determine OVD when compared to $\mathrm{FEF}_{25-75 \%}$; the systems for obtaining these parameters are different. There is time verification in the FVC maneuver, which determines FEV ${ }_{1}$. The $\mathrm{FEF}_{25-75 \%}$ is recorded by calculating the mean flux in the middle portion of the FVC curve, dividing the volume expired by the time spent between 25 and
$75 \%$ of the exhalation. Flows present greater variability in normal individuals (27). Spirometry with abnormal flow was not related to the decrease in $\mathrm{FEV}_{1}$ in a longitudinal study (28). The recording of FEF $25-75 \%$ in series could make it more variable, as it should be determined through the same volume of the initial curve, which is not possible in the spirometry systems used (3). These reasons could explain the presence of a decrease in $\mathrm{FEV}_{1}$ without changing the $\mathrm{FEF}_{25-75 \% \text {. }}$.

The autonomic modulation, RMSSD and SD1, which characterize the parasympathetic action, were higher in athletes compared to sedentary individuals, suggesting that the parasympathetic activity was increased. These results corroborate previously described studies reporting increased parasympathetic activity in athletes $(29,30)$. There was a lower resting HR in the athletes, indicating a relation of these indices with higher HRV. The increase in vagal activity may be related to the increase in the SDNN and SD2 indices observed in the athletes, indicative of overall variability.

Maladjustments in sympathetic and parasympathetic tone can induce disease (14). The greater parasympathetic tone found in the swimmers could be an adjuvant trigger for the OVD found in these patients. The higher the parasympathetic activation, the greater the bronchoconstriction (10). A limitation of this study is the limited number of swimming athletes, as it is a population of high-performance athletes with a specific training workload.

\section{Conclusion}

It was observed that the EIB test identified, more frequently, the presence of bronchospasm in the general population. Among the swimmers there was a reduction in the FEV1/FVC ratio. There was higher HRV in the population of swimmers studied.

\section{References}

1. FitzGerald JM, Bateman ED, Boulet LP, Cruz AA, Inoue H, Haahtela T, et al. Global Innitiative for Asthma. Global strategy for asthma management and prevention: updated 2015 [cited 2015 Jul 6]. Available from: www.ginasthma.org. 
2. IV Diretrizes Brasileiras para o manejo da asma. J Bras Pneumol. 2006;32(Supl 7):S447-74.

3. Pereira CA. Diretrizes para testes de função pulmonar. J Bras Pneumol, 2002;28(Supl 3):S1-221.

4. Pedersen SE, Hurd SS, Lemanske RF, Becker A, Zar HJ, Sly PD, et al. Global strategy for the diagnosis and management of asthma in children 5 years and younger. Pediatr Pulmonol. 2011;46(1):1-17

5. Akinbami LJ, Jeanne E, Moorman JE, Bailey C, Zaharan HS, King M, et al. Trends in asthma prevalence, health care use, and mortality in the United States, 20002010. NCHS Data Brief. 2012;94:1-8.

6. Harris DJ, Atkinson G. International Journal of Sports Medicine - ethical standards in sport and exercise science research. Int J Sports Med. 2009;30(10):701-2.

7. Eliasson AH, Philips YY, Rajagopal KR, Howard RS. Sensitivity and specificity of bronchial provocation testing. An evaluation of four techiniques in exerciseinduced bronchospasm. Chest. 1992;102(2):347-55.

8. Holzer K, Brukner P. Screening of athletes for exercise-induced bronchoconstriction. Clin J Sport Med. 2004;14(3):134-8.

9. Teixeira RN, Teixeira LR, Costa LAR, Martins MA, Mickleborough TD, Carvalho CRF. Exercise-induced bronchoconstriction in elite long-distance runners in Brazil. J Bras Pneumol. 2012;38(3):292-8.

10. Barnes PJ, Thomson NC. Neural and humoral control of airways. In: Barnes PJ, Drazen JM, Rennard SI, Thomson NC. Asthma and COPD: Basic Mechanisms and Clinical Management. 2nd ed. San Diego: Elsevier; 2008. pp. 381-98.

11. Cassol VE, Trevisan ME, Moraes EZC, Portela LOC, Barreto SSM. Broncoespasmo induzido pelo exercício em crianças e adolescentes com diagnóstico de asma. J Bras Pneumol. 2004;30(2):102-8.

12. Crapo RO, Casaburi R, Coates AL, Enright PL, Hankinson JL, Irvin CG, et al. Guidelines for Methacholine and Exercise Challenge Testing-1999. This official statement of the American Thoracic Society was adopted by the ATS Board of Directors, July 1999. Am J Respir Crit Care Med. 2000;161(1):309-29.
13. Vanderlei LCM, Silva RA, Pastre CM, Azevedo FM, Godoy MF. Comparison of the Polar S810i monitor and the ECG for the analysis of heart rate variability in the time and frequency domains. Braz J Med Biol Res. 2008;41(10):854-9.

14. Vanderlei LCM, Pastre CM, Hoshi RA, Carvalho TD, Godoy MF. Noções básicas de variabilidade da frequência cardíaca e sua aplicabilidade clínica. Rev Bras Cir Cardiovasc. 2009;24(2):201-17.

15. Niskanen JP, Tarvainen MP, Ranta-aho P, Karjalainen PA. Software for advanced HRV analysis. Comput Methods Programs Biomed. 2004;76(1):73-81.

16. Miller A. Spirometry and maximum expiratory flowvolume curves. Pulmonary function tests in clinical an occupational lung disease. Orlando: Grune \& Stratton; 1986. p. 15-51.

17. Kivity S, Solomon A, Schwarz Y, Trajber I, Topilsky M. Evaluation of symptomatic subjects with low forced expiratory ratios $\left(\mathrm{VEF}_{1} / \mathrm{VC}\right)$. Thorax. 1994;49(6):554-6.

18. Mickleborough TD, Stager JM, Chatham K, Lindley MR, Ionescu AA. Pulmonary adaptations to swim and inspiratory muscle training. Eur J Appl Physiol. 2008;103(6):635-46.

19. Rong C, Bei H, Yun M, Yuzhu W, Mingwu Z. Lung function and cytokine levels in professional athletes. J Asthma. 2008;45(4):343-8.

20. Miller MR, Hankinson J, Brusasco V, Burgos F, Casaburi $\mathrm{R}$, Coates A, et al. Standardisation of spirometry. Eur Respir J. 2005;26(2):319-38.

21. Fiks IN, Albuquerque ALP, Dias L, Carvalho CRF, Carvalho CRR. Occurrence of asthma symptoms and of airflow obstruction in amateur swimmers between 8 and 17 years of age. J Bras Pneumol. 2012;38(1):24-32.

22. Oliveira VV, Isidório UA, Santos WM, Sousa MJS, Oliveira AV. Análise comparativa da função respiratória em praticantes de atividade física e indivíduos sedentários. Enc Bioesfera. 2012;8(15):1920-30.

23. Okura RT, Schivinski CIS. Six-minute walk test in pediatrics: the relationship between performance and anthropometric parameters. Fisioter Mov. 2013;26(1):219-28. 
24. Orestein DM. Asthma and sports. In: Bar-Or 0. The child and the adolescent athlete. London: WileyBlackwell; 1996. p. 433-54.

25. Ram FS, Robinson SM, Black PN, Picot J. Physical training for asthma. Cochrane Database Syst Rev. 2005;(4):CD001116.

26. Courteix D, Obert P, Lecoq AM, Guenon P, Koch G. Effect of intensive swimming training on lung volumes, airway resistance and on the maximal expiratory flowvolume relationship in prepubertal girls. Eur J Appl Physiol Occup Physiol. 1997;76(3):264-9.

27. McFadden ER, Linden DA. A reduction in maximum mid-expiratory flow rate: A spirographic manifestation of small airway disease. Am J Med. 1972;52(6):725-37.

28. Stanescu DC, Rodenstein DO, Hoeven C, Rober A. "Sensitive tests" are poor predictors of the decline in forced expiratory volume in one second in middle-aged smokers. Am Rev Respir Dis. 1987;135(3):585-90.
29. Silva VP, Oliveira NA, Silveira H, Mello RG, Deslandes AC. Heart rate variability indexes as a marker of chronic adaptation in athletes: a systematic review. Ann Noninvasive Electrocardiol. 2015;20(2):108-18.

30. Aubert AE, Seps B, Beckers F. Heart rate variability in athletes. Sports Med. 2003;33(12):889-919.

Received in 22/10/2015

Recebido em 22/10/2015

Approved in 07/28/2016

Aprovado em 28/07/2016 